\title{
How 'Intercultural' is Education in Greece? Insights from policymakers and educators
}

\begin{abstract}
Schools in Greece, particularly in inner-city areas, have seen a considerable increase in the number of migrant students over the past two decades. In this article, we discuss the intercultural education policy, which was introduced in 1996, in response to the migration and diversity the country has seen since the mid 1980s. We explore how policymakers and other stake-holders in the field of education have defined the notion of interculturalism and its implementation in schools. Our discussions draw on two separate studies, which used very similar tools and methods to elicit information. The article provides new insights from educators about how to respond to Greece's diverse student population. The results not only highlight gaps between government policy and school practice, differences between traditionalists and progressivists, but also show that Greece has still a long way to go, to leave behind its ethnocentric image and fully implement intercultural education within all public schools, not only in the so-called intercultural schools.
\end{abstract}

Keywords: Intercultural education, policymakers, educational policy, diversity, interculturalism, multiculturalism, Greece 


\section{Immigration, National Identity and Citizenship in post-1989 Greece}

Greece is undergoing considerable demographic, economic and socio-political change. The notion of a culturally homogeneous nation-state and identity has been challenged by a series of events including the intertwined processes of European integration, globalization, migration and the foundation of the Former Yugoslavian Republic of Macedonia (Faas 2011a). This despite the fact that Greece, in its past, had not been a culturally homogenous society, given the historical minorities, notably the Muslim minority in western Thrace (on the north-western border with Turkey), which consists of approximately 60,000 Muslims of Turkish origin, 42,000 Pomaks (slavophone Muslims) and 18,000 Muslims of Romany origin (see Antoniou 2005; Markou 1994). Since the fall of the Iron Curtain in 1989, Greece has experienced an unprecedented wave of immigration, which has altered the composition of its resident population significantly and irreversibly. Greece was transformed from a traditional emigration country in the 1960 s and 1970 s to an immigration one from the late 1980 s (Markou 1994).

In contemporary societies, national identity with its stability and territorial attachment arguably reassures individuals who are perturbed by the dislocation, isolation and insecurity of globalised life (Guibernau 2007). However, the nation-state, still, has a crucial role in the articulation of identities that allow individuals to participate in the globalised world. In the case of Greece, Islamic identity was, and still is, viewed in the education system and wider society as the 'other', different from Greekness, and forms the basis for social exclusion of this group which is not seen as being part of the 'nation'. Though this is a crucial situation for consideration, it is not within the aims of this article.

From a comparative European perspective, several countries have been transformed from sending to receiving societies over the last three decades, and are facing similar societal challenges around migrant integration. In English-speaking countries (such as Australia, 
Britain, the United States) the term 'multicultural' has been used as a policy term and has caused numerous debates. In non-English speaking countries, the EU, Council of Europe, UNESCO and other international organisations, the term 'intercultural' is preferred when referring to policies and practices. A comparison of migration policies in European countries shows that the majority of them follow assimilationist exclusionary practices. In this article, we use 'intercultural' when referring to policies and practices and 'multicultural' when describing the reality on the ground in schools and societies at large except for the term 'intercultural schools' which is used officially by the Greek Ministry of Education, Life-Long Learning and Religious Affairs (hereafter MoE) for this type of bilingual schools.

Few other countries in Europe (with the exception of Ireland, where the Catholic Church has considerable control over education) demonstrate so intense connections between religion and national agendas. In Greece, since the acquisition of its independency in 1830 as a nation-state, the Orthodox Church has imposed its sovereignty with the formation of an ethnically-based and Orthodox identity. Socio-historically, the construction of a Greek identity based on 'ethnos', 'ancient Greece' and 'Orthodox religion' have been important elements for strengthening the nation-state against the perceived 'others' (i.e. neighbouring countries). Between 1955 and 1974, a total of 1,304,763 emigrants left Greece for northern and central European countries, America and Australia, seeking a better way of life.

During the last two decades Greece has become the host of more than a million returning co-ethnics, co-ethnic immigrants and foreigners - these groups accounting now for more than $10 \%$ of the total resident population. In particular Greece received in the late $1980 \mathrm{~s}$ and during the 1990s approximately 150,000 co-ethnic returnees from the former Soviet Union (Pontic Greeks) and nearly 240,000 ethnic Greek Albanians from southern Albania (Voreioipirotes). In addition during the 1990s and 2000s Greece has experienced significant inflows of economic migrants from eastern European, Asian and African countries. The total 
legal immigrant population is currently estimated at just under 700,000, the largest groups being Albanians, Romanians, Bulgarians, Georgians, Ukrainians, Pakistani, and Bangladeshis. It should be noted here that these population changes might have influenced the opinions, thoughts and positions of policymakers and educators interviewed in 2001 and 2007. Similarly, the data might have been affected by the very fact that in 2001 the country was governed by centre-left Kostas Simitis compared to centre-right Kostas Karamanlis in 2007 leading to potentially different philosophies of migrant integration. The data should therefore be read in light of these political and societal realities.

The 2001 immigration law (Government Gazette 2001) had achieved only minor steps to remove the existing discrimination and prejudice towards immigrants, particularly with regard to citizenship acquisition, between the two main groups: co-ethnic returnees (homogeneis), who were either Greeks born in Greece who had immigrated or with Greek origins (mainly because of their ancestors national background), and 'foreigners' or 'aliens' (allogeneis/alloethneis allofonoi). The salient preference for the homogeneis group had resulted in, what some academics had referred to as, a 'hierarchy of Greekness', including: (a) 'real Greeks' whose parents were both Greeks and born in Greece, (b) those who had Greek origin either from one of their parents or from their grandparents (Pontic Greeks) and (c) 'foreigners' whose parents did not have Greek nationality (Triandafyllidou and Veikou, 2002). Contrary to the native minorities (i.e. the Muslims of western Thrace) and 'foreigners', co-ethnic migrant populations are considered as integral part of the nation and are seen as relatively easy to integrate into the mainstream culture and education system. Some of the more recently arrived groups, notably Pakistani and Bangladeshis, pose a greater challenge to Greek society because of their different phenotype and Muslim religion.

In light of $10 \%$ immigrant population, Greece is slowly and to a certain extent reluctantly adapting its education and citizenship policies. A first step in this direction has 
been the reform of the citizenship law in March 2010 when the Social Democrat government adopted Law 3838 entitled 'Greek citizenship and political participation of homogeneis and legally resident migrants and other regulations' (Government Gazette 2010). The new Law 3838 amends Law 3284/2004 on the Ratification of the Code of Greek Citizenship (Government Gazette 2004). The new law also reduces the naturalization process of EU longterm residents from ten to seven years. It is expected that approximately 500,000 legal migrants and about 250,000 second-generation children will acquire Greek nationality. As a result of this new demographical situation, in the municipal elections in October 2010, more than 266,000 legally residing migrants were entitled to vote for first time.

It seems that the general frame of the new citizenship Law 3838/2010 is very positive towards migrants, especially for second-generation children. Migrant children born in Greece from legal migrant parents living in Greece at least five years can acquire Greek citizenship by birth. In addition, migrant children who have successfully completed six years of continuous schooling in Greece can also acquire citizenship. Until recently, second or even third generation immigrants were not entitled to Greek citizenship, unless their parents were naturalized, something which happened only in a few cases. This was a deeply controversial and divisive issue, against which many NGOs, migrant associations and European organizations, had expressed their concerns. In brief, with the new law there is a shift from the 'ius sanguinis' approach to a policy of 'ius soli'.

\section{Major educational responses to migration-related diversity}

Despite large-scale immigration since 1989, it was not until 1996 that Greece responded officially to the presence of migrant and repatriated pupils in public schools with Law 2413/1996 entitled 'Greek Education Abroad, Intercultural Education and Other Provisions' (Government Gazette 1996). This legalization of intercultural education represented a shift 
from earlier notions of 'foreigner education' and the 'deficit hypothesis' to the 'difference hypothesis', which meant that policymakers were committed to recognize, albeit to a limited extent, cultural and ethnic differences in Greece (Damanakis 2005).

The Law consists of eleven chapters, of which only one referred to intercultural education. According to Article 1, the aim of intercultural education is to organize and run schools to provide education to young people who are educationally, socio-culturally or instructionally distinct. According to Article 2, in the intercultural education schools the programmes of the respective public schools are implemented, which are adapted to the special educational, social, cultural or educational needs of their pupils. Article 35 regulates the functioning of intercultural schools where special curricula can be implemented and the ratio of pupils per class is minimized. Article 36 introduces issues of the teaching staff of the intercultural schools and Article 37 focuses on administration of the intercultural schools. Special educational provisions and measures which refer to the functioning of public schools were discussed at later stage in the 1999 Precedential Decree $\Phi 10 / 20 / \Gamma 1 / 708$.

Law 2413/96 legitimized the foundation of intercultural schools by invoking cultural diversity. Apart from the normal public curriculum, intercultural schools provide courses on the language and culture of the country of origin of migrant pupils, up to four hours per week. Since 1996, a total of 26 such schools have been established across the country - thirteen primary schools, nine gymnasia (first cycle of secondary education) and four lykeia (second cycle of secondary education). Out of 15,174 state schools, these intercultural schools correspond to $0.17 \%$, whereas there are $12 \%$ of students with a migrant background (excluding Muslims and Roma children) in Greek primary schools (see Palaiologou and Evangelou 2011).

With the 1999 Presidential Decree $\Phi 10 / 20 / \Gamma 1 / 708$, the final scheme and context of 'reception' and 'tutorial or support' classes was established. According to this, public schools 
with a high percentage of migrant pupils could set up reception or tutorial classes. A reception class is a 'parallel' class, which minority ethnic students attend during the language lesson. It provides five to ten hours of instruction per week, taking into account how many years the student attends the school of the host country, how many years of remedial instruction s/he has followed and what her/his linguistic competency of the second language is. In contrast, support classes provide some tuition after school. In schools which provide support classes, tuition provided for each pupil or group of pupils varies between three and ten hours per week, based on pupil's learning needs (Palaiologou 2004).

Law 2413/96 and the Precedential Decree in 1999 have not explicitly promoted an intercultural policy towards pupils with different cultural characteristics. On the contrary, the educational praxis reveals the law's underlying discriminatory approach towards migrant pupils. Newcomers in particular encounter obstacles in Greek public schools, associated either with discrimination from native peers and parents, or with lower educational expectations on the part of their teachers, and with a lack of educational support measures that would help them to achieve higher school grades and have higher self esteem.

For those migrant pupils who attend one of the 26 intercultural schools evidence shows that these schools are preferred usually by migrant parents who come from specific countries (mainly from English speaking countries, from the former Soviet Union) rather than native Greeks. As a result, these schools function more as ghettos for migrant pupils rather than real intercultural learning places that integrate both migrant and native pupils.

The 1999 Presidential Decree left the initiative to organize mother-tongue language teaching to the prefectures without clear budget lines. However, our fieldwork indicated that there have only been sporadic private initiatives with the support of some teachers and parents for Albanian, Ukrainian and Arabic language classes to take place in their schools during evening hours. This was despite the fact that Article 72 of the former immigration law 
(Government Gazette 2005) provided the possibility for the Minister of Education to arrange mother-tongue teaching and culture lessons. In addition, three educational programmes were carried out, between 1997 and 2007, in collaboration with Greek universities, supported by the European Social Fund, with the aim of supporting migrant pupils participate in society whilst maintaining their ethno-cultural identities. These initiatives were targeted toward three different groups of pupils: (a) the historical Muslims of Thrace; (b) Roma students $(80,000$ to 120,000, according to Markou 1994); (c) repatriated and 'foreign' students.

In September 2010, the MoE assigned to university departments the administration and implementation of new intercultural educational programmes aimed at 'migrant and repatriated' pupils, 'Roma' children, and native Greek students. This new phase lasts until 2013, and approximately 20 million Euros in EU funds have been earmarked for the development of new curricula for migrant pupils. One would hope that amongst the priorities that will be set are the development of special textbooks and curricula and the introduction of new educational support measures for migrant pupils and their parents.

According to the Institute for Greek Diaspora Education and Intercultural Studies (IPODE) affiliated to the MoE until 2010 and responsible for collecting educational data, in 2007-08 there were 138,193 migrant and repatriated Greek students. These corresponded to $10 \%$ of the school population (Palaiologou and Evangelou 2011). Recent data from the MoE (2010) show that migrant pupils come from more than 100 different ethnic backgrounds. Amongst the groups represented are Albanian (118,147), Bulgarian (7,773), Romanian $(5,119)$, Georgian (2,322), Russian (1,520), Polish (1,264), Indian (1,121), Armenian $(1,102)$, Egyptian (1,021), Syrian (1,004), Moldovan (894), Ukrainian (875) and Filipino (609).

Comparing the multicultural education situation of the last decade with the situation before 2000, there are several important differences: firstly, from the mid 1980s until late 1990s, the majority of the migrant population that entered Greece were of 'Greek origin'. 
Secondly, during the first decade of the 21 st century, there is a significant flow of foreign migrants to Greece from many different countries, with much smaller numbers of 'Greek origin' migrants. Thirdly, since 2010, there have been important changes in the functioning of the social system, reflected in the education domain, because of the economic crisis that the country is engulfed in. As a result, two important organizations responsible for the social and educational integration of migrants in Greece, was abolished: the Migration Policy Institute (IMEPO) and the 'Institute for the Greek Diaspora Education and Intercultural Studies' (IPODE). Similar cutbacks and closures of organizations for migrant students are also seen elsewhere in Europe in countries hit hard by the recession since 2008, notably Ireland.

\section{Conceptualizing Multicultural and Intercultural Education}

Our study explores what 'intercultural' education in Greece really means and how it is implemented. We address this question by analyzing the discourses of policymakers and educators in relation to how intercultural education in the first decade of the new millennium has been implemented and where some of the main obstacles lie. The education sector is arguably one of the most sensitive and politically charged areas of public policy because of its determining role in balancing cultural diversity and social cohesion.

To contextualize our discussions, it is important to clarify the concept of multicultural education compared to intercultural education. The majority of proponents of interculturalism emphasize communication, interaction and dialogue (Gundara 2000), while most of those in favour of multiculturalism argue that reciprocity, dialogue and civic integration are central to most, if not all, contemporary accounts of multiculturalism (Banks 2004). According to the United Nations Educational, Scientific and Cultural Organization $(2006,17 \mathrm{f}$.$) :$

The term multicultural[ism] describes the culturally diverse nature of human society. It not only refers to elements of ethnic or national culture, but also includes linguistic, 
religious and socio-economic diversity. Intercultural[ism] is a dynamic concept and refers to evolving relations between cultural groups. It has been defined as the existence and equitable interaction of diverse cultures and the possibility of generating shared cultural expressions through dialogue and mutual respect. (...) Multicultural education uses learning about other cultures in order to produce acceptance, or at least tolerance, of these cultures. Intercultural education aims to go beyond passive coexistence, to achieve a developing and sustainable way of living together in multicultural societies through the creation of understanding of, respect for and dialogue between different cultural groups.

European societies rely on different models to address cultural and religious diversity in education. For example, Germany, Greece and Ireland prefer the term interculturalism and intercultural education. By contrast Britain, the Netherlands, Australia, the United States and Malaysia, have historically worked with the concept of multiculturalism (Nieto and Bode 2007). Greek academics started an intense debate on the concept of intercultural education in the mid-1980s. For example, Gotovos and Markou (1984) criticized the assimilatory educational policy and practices and so proposed that students should be allowed to retain their own cultural elements during their stay in a reception country without being considered as a disadvantage. 'It is within the interest of the school', Markou $(1994,40)$ argued, 'not to assimilate them culturally through the logic of conformity and homogeneity, but to help them acquire the necessary knowledge and skills which will allow them to improve their school performance and successfully gain acceptance from their fellow students to be different'.

According to Banks (2004), multiculturalism is a concept, an educational reform movement, and a process. For Banks, the intention of multicultural education is to create an environment offering equal education opportunities to students from different racial, ethnic and socio-economic backgrounds, thus preserving and promoting diversity while supporting students in becoming critical thinkers and responsible democratic citizens. To carry out these goals through multicultural education, Banks had identified five crucial dimensions: content integration, knowledge construction, prejudice reduction, equity pedagogy, and an 
empowering school culture. These five components have a strong impact on the educational achievement of all students, not only ethnic minorities, and also improve intergroup relations among students and staff (Zirkel 2008).

At a time when many see a crisis for the concept of multiculturalism and its potential for integrating ethnic minorities (see the analyses in Modood, Triandafyllidou and ZapataBarrero 2005), it seems that policymakers are increasingly emphasizing social cohesion and return to either an assimilationist approach which emphasizes national culture and values, or an integrationist approach which recognizes cultural diversity but often leans toward assimilation (see also Vertovec 1999; Olsen 1997). The Netherlands, for example, has been a forerunner in multiculturalism since the $1980 \mathrm{~s}$, but has shifted recently towards integration with the introduction of integration courses for newcomers and a civic test to be undertaken by prospective migrants before departure from their country of origin (see Ter Wal 2007; Vasta 2007). On the other hand, in the face of mounting civil unrest and social exclusion of second-generation immigrant youth, the French government reasserted its civic Republican integration model banning religious symbols from schools (see Kastoryano 2006; Guiraudon 2006).

The idea of interculturalism, as distinct from multiculturalism, has, hitherto, more commonly been found in Dutch and German accounts of integration, particularly in education (see Gundara 2000). According to Wood, Landry and Bloomfield (2006, 9) 'communication' is the defining characterisitic of interculturalism. They argue that communication is the central means through which 'an intercultural approach aims to facilitate dialogue, exchange, and reciprocal understanding between people of different backgrounds'. Given the diversity of migrant countries of origin, the result is not diverse communities but rather a churning mass of languages, ethnicities, and religions, all cutting across each other and creating what Vertovec (2007) has called a 'super-diversity'. It is often argued that multiculturalism places 
too much emphasis on difference and diversity, on what divides us more than what bonds societies together (Goodhart, 2004). This leads to fragmentation and disunity which can be overcome through emphasizing inclusion and cohesion. Our view is that multiculturalism can be reconceptualized so that it addresses interaction and integration and, thus, redefines interculturalism as a form of inclusive or integrative multiculturalism (see Faas 2010).

In a similar vein, Modood $(2007,14)$ argues that multiculturalism has multiple meanings and is 'a form of integration'. Multiculturalism, he says, goes beyond a liberal toleration of difference and is 'more active in relation to minority identities and majority identities' (ibid., 67). In other words, the state promotes difference (diversity) and solidarity (cohesion) at the same time. Multiculturalism, just like interculturalism, does not encourage strong multicultural identities and weak common identities. Such a re-conceptualization of multiculturalism might make it easier for both government representatives and school officials to work with because it ultimately attempts to bridge an ideological divide that has been central to conventional academic debates where:

\begin{abstract}
Multiculturalism tends to preserve a cultural heritage, while interculturalism acknowledges and enables cultures to have currency, to be exchanged, to circulate, to be modified and evolve (...) [Interculturalism] is concerned with the task of developing cohesive civil societies by turning notions of singular identities into those of multiple ones, and by developing a shared and common value system and public culture. In building from a deep sharing of differences of culture and experience it encourages the formation of interdependencies which structure personal identities that go beyond nations or simplified ethnicities (see Sze and Powell 2004; Booth 2003).
\end{abstract}

There are those who view multicultural education as a response to the diversity and fragmentation of European societies (for example, Modood 1997, 2007), and others who describe it as 'a critique of the Eurocentric and in that sense monocultural content and ethos of much of the prevailing system of education' (Parekh 2000, 225). The general ethos 
pervading the educational system, Parekh contends, highlights the glory and uniqueness of European civilization and underplays or ignores the achievements and contributions of others.

Parekh (2000) argues that a multicultural curriculum needs to satisfy two conditions. Firstly, it should not be unduly narrow. Ideally, it should familiarize students with the major representative forms of the subject in question, concentrate on some of them, and so stimulate them that they follow up the rest on their own culture. Secondly, the way a curriculum is being taught is critical. The author suggests that it is not enough to include different religions, cultures and texts in the curriculum since these elements need to be brought into a dialogue. Multicultural Education, Parekh concludes, neither undermines common culture and social unity, nor distorts history. Instead, it is committed to the basic values of liberal society, broadens them to include others, and helps create a plural and richer common culture. Moreover, it fosters social cohesion by enabling students to accept, enjoy and cope with diversity. We will return to this notion of balancing social cohesion and migration-related diversity later in the article when we discuss how Greek policymakers work with these concepts, and how interculturalism is conceptualized within both the MoE and other educational institutions, as well as within schools.

\section{Research Methodology}

The article draws on data from two separate studies which explored the responses of stakeholders in education to the increasing migration-related diversity in Greece and notions of intercultural education. Both studies involved semi-structured interviews with policymakers in Greece, and several of the main questions addressed were either the same or very similar allowing for a fruitful comparison of responses over time. The data used for this paper were collected for studies with a slightly different purpose; yet despite somewhat different original aims we chose aspects and question similar to both studies for analysis. 
The first study $^{2}$, conducted in 2001, included respondents from three major categories: (a) five officials from the MoE (General Secretary of the Education of Greek Diaspora and Intercultural Education), school counsellors at the Pedagogical Institute which is an independent institution that oversees the drafting and revisions of curricula and textbooks, the Special Counsellor of Intercultural Education from the Pedagogical Institute of the MoE, (b) six school representatives such as head teachers at intercultural and mainstream schools who hold an administrative position, (c) primary school teachers in the municipality of Athens. Hereafter, head teachers and teachers are called educators. This article draws primarily on the responses of the five government officials and six school representatives. The selection of policymakers was based on their potentially contradicting views regarding the implementation of Law 2413/96 on intercultural education in Greece, outlined earlier. Analyzing the range of discourses would reveal patterns of social inclusion and exclusion of minority ethnic students within the Greek educational context. In the larger project, these interviews were triangulated with informal observations in nine intercultural classrooms in three intercultural schools and in nine mainstream classes in order to obtain a richer insight into the factors affecting migrant integration and education.

The design of the second study ${ }^{3}$, conducted mainly in 2007 , combined an analysis of a selection of history, geography and civic education curricula of the Greek, German and English school, and semi-structured individual interviews with policymakers conducted in people's place of work in Athens, Stuttgart, London and Brussels (Faas 2011b). For the construction of the interview protocol of the second study, the interview protocol of the first study was taken into consideration. 30 policy interviews were conducted including thirteen in Greece, seven in Germany, six in England and four in Brussels within the DirectorateGeneral for Education and Culture. The aim of the larger project was to explore how curricula and education policy stakeholders balance cultural diversity and social cohesion, 
and address how national, European and multicultural values are or could be combined in education policymaking. For the purposes of this article, only the thirteen interviews with representatives in Greece were included. These included senior officers from the MoE, officials from the former IPODE which was affiliated within the MoE responsible for conducting educational studies, advisors from the Pedagogical Institute; representatives from the Greek Federation of Secondary State School Teachers (OLME), and the heads of District Offices responsible for secondary education in central Athens. The interviews were carried out either by native speakers or with the help of an interpreter. In both cases, the interview schedules with key stakeholders in Greece had questions addressing the provision of intercultural education and its current implementation. This ensured a comparison of the evolving opinions of key actors between 2001 and 2007, and highlighted main differences and similarities with regard to defining and implementing intercultural education.

All interviews were recorded, transcribed and then analyzed following a content analysis approach, whereby the thematic categories emerged from the deconstruction of the multiple meanings from the responses of recipients. We explored the ways in which policymakers and stakeholders define interculturalism and multiculturalism; how they thought intercultural education should be implemented; and more broadly how they respond to the challenge of balancing diversity and societal cohesion.

It is obvious that our own analysis can only provide an account of our readings of the data and other researchers might well put together the truths in different ways. Our analysis is aimed at identifying best practices and at highlighting issues for policy development and improvement. The identities of all respondents were protected by using pseudonyms.

\section{Intercultural Education in $21^{\text {st }}$ Century Greece: Research Findings}

Within the policy community and within the MoE and its different levels of policy implementation there are officials that have very different understandings of intercultural 
education. Our combined studies have identified a range of meanings associated with this concept in contemporary Greece. For example, senior policy officers in the MoE stressed that all students have a right to education and that compulsory schooling is implemented without regard to the parents' legal or undocumented migrant status. However, when it came to providing concrete examples, interviewees could hardly go beyond notions of equality. Integration seemed to be equated to a certain extent with assimilation even though this was formally rejected. Ms. Doxiadis, whilst discussing the importance of helping minority ethnic students integrate, mentioned that 'I have christened a foreign student and she is now a firstyear medical student'. This example was flagged with a lot of pride of how this student had successfully 'integrated', but the reference to the christening suggests that, following the national pattern, the main point was to become Orthodox Greek and speak Greek. Mr. Konstantinitis, the head of a District Office in Athens, applauded 'the non-Greek mother tongue pupils' for being 'among the best in reciting their poems, dancing the Greek traditional dances [during national commemorations on March 25 Independence Day and October 28 Ochi Day]'. Generally, however, MoE officials like Mr. Dranias sounded politically correct:

Mr. Dranias: [The main goal is] to integrate them in the education system so that they also have equal opportunities and access to education. To reduce school drop-out rates. (...) The needs of life and society always vary which means that today as citizens, us too, of the EU we see things differently. And the needs of education are also larger. Because here we have the human right to education, regardless of gender, nationality, besides the Constitution foresees that and gives the right to all children, that all people can take part in Hellenic education regardless of their country of origin, gender or religion. Very important. (...) Our education has humanist values and it has never separated [foreign students from other students]. Children can show their cultures to a certain extent. This can be supported by parents as well. There are several special days; for example 'Friendship Day' which take place in schools. 
In contrast to this appraisal of Hellenic education and the fixed, static nature of the Greek education system into which non-Greeks should somehow integrate or assimilate, a more progressive view of responding to diversity was found amongst officers from IPODE such as Ms. Theodoris and within OLME. Here, the notion of intercultural education involved not only exchange and knowledge of other cultures but also a redefinition of national identity through interaction with ethnically diverse students and intercultural dialogue:

\begin{abstract}
Ms. Theodoridis: We are trying to open up the school generally, for everyone. For native students as well, this is our goal. The basic element, from which we start in conferences and workshops, is that intercultural education concerns native [Greek] students as well. In practice this is much more difficult. We might say that the basic element is the interaction which helps the native and 'foreign' students but of course in practice, when you have children in primary and secondary school that don't speak Greek at all, it is understandable that the weight is going to be laid on language learning first. However, the objective of the school shouldn't be to transform them into Greeks, neither from a linguistic nor cultural point of view. Of course, I [the educator] can also take elements from these students. This is my own opinion.
\end{abstract}

The ethnocentricity of the Greek education system and the difficulty of combining national and intercultural values have been already noted by, among others, Avdela (2000) who argues that the continuity of Hellenism from antiquity to the present constitutes an important part of Greekness that is particularly reinforced through the teaching of history. Although there have been efforts to train teachers in intercultural pedagogy and reception classes are provided for non Greek speaking pupils, overall there is no concerted effort to accommodate cultural and religious diversity in schools. Difference is mainly seen as a 'problem' of the foreign children. The ideal outcome is their assimilation into the mainstream. Recent research suggests that ethnic diversity is tolerated but not accepted in Greek schools: Greek parents, children and teachers argue that migrant children have a negative impact on the quality of 
education provided. Migrant parents are aware of the stereotype and also sometimes deplore the poor quality of the school that their child attends, blaming it on the fact that the school has too many migrant children and that teachers are indifferent about their children's education. Overall they also express a feeling of being tolerated, not accepted, in Greek society. Moreover, the predominant attitude towards diversity is one of tolerance that goes hand in hand with the unquestioned acceptance of the majority religion, the majority language, the majority ethnicity in Greek school life. This is well in line with the dominant discourses on national identity in Greece and the dominant tradition of only accommodating diversity, if at all, at the individual but not at the collective level (Triandafyllidou 2011).

\section{Intercultural versus multicultural education}

In 2001, when asked about differences between intercultural and multicultural education, many teachers came up with definitions not so dissimilar from the relevant academic literature in this area and ongoing political debates:

\footnotetext{
Mr. Papadakis: These two terms seem to be very different to me! Like day and night. In multicultural education we have just the co-existence of different cultures but this doesn't mean that there is communication and exchange among these cultures. On the other hand, I believe that in intercultural education there is an interaction and communication among the persons that have a different cultural background. [...]

Ms. Klitsa: Multicultural is that kind of education which includes many different cultures together. It should take into consideration the needs of students coming from different countries and find ways how we can manage the better co-existence among these students. Intercultural education, I think, is something different (...) but I can't pinpoint the difference! However, I have the feeling that this is something different.
}

The slight confusion underlying the latter respondent who is unable to pinpoint the difference between the two concepts reflects the argument of Lentin (2005), among others, that 
interculturalism is merely an 'updated version' of multiculturalism. And if that is the case we still do not know exactly what it is that is being 'updated'. Arguably, interculturalism and intercultural education is committed to a stronger sense of the whole, a sense of social cohesion rather than an emphasis of what drives communities apart; it is something more than just the co-existence of different cultures (as Ms. Klitsa pointed out).

Many Greek educators are insufficiently prepared for the two-way process underlying intercultural education. The 1996 law, mentioned earlier, required that teachers should be sensitive towards 'foreign' and repatriated pupils. However, the following excerpt from a teacher interview in 2001 reveals the limited education that most teachers have on intercultural matters. Moreover, it reveals the anxiety of the in-service teachers that are insecure and unready to cope with the difficulties that they face in their classroom. These difficulties are various and include school adjustment difficulties that the students appear to have, lack of appropriate schoolbooks, lack of appropriate education in methodology and teaching methods. The majority of teachers did not receive any kind of special education on intercultural matters during their undergraduate studies:

Mr. Koletsos: I think this could happen by accepting the cultural heritage of our different students. But this is not only the case. We have to be trained on different styles of teaching and school practices, methodological approaches in order to be culturally ready to cope with the multiple difficulties that arise in the classroom. [...]

Ms. Giannitsi: Not at all! I was lucky because I attended a training seminar entitled "School and Social Inclusion of the immigrant and repatriated pupils". We attended lessons of Psychology, Pedagogy and Bilingual Education.

Until recently, there were no courses on intercultural or multicultural education during teacher training and intensive seminars had to be organized in an attempt to sensitize the workforce. In 2001, teachers simply attended some sessions in the Sociology of Education 
module, mainly about the non-native American population. On the contrary, individual initiatives have remained the most important catalyst of intercultural education in contemporary Greece. Thus there is still some way to go, according to Ms. Theodoris and others, before the cultural and linguistic capital students bring to school is fully appreciated. Ms. Arvanitis from the Centre for Intercultural Education went so far as to claim that even among many progressive policy officers there has been no conscious reconsideration of what it means to be Greek today, and that there is generally a hierarchy of 'race' and a feeling that the Greek culture is somehow superior to other cultures.

\section{Policy-practice gaps in Greek education}

According to the school principals interviewed as part of the first study in 2001 , there is a gap between Law 2413/96 and its implementation. Everyday school practice reveals that the school does not take advantage of all the available means in order to become more inclusive for all students. For example, the implementation of the Law allows the teaching of a foreign language to students where there are sufficient numbers of foreign pupils; also, in the Law there is provision for bilingual teachers, but this measure is considered very radical for the Greek educational system according to Greek teachers and principals. Besides reproducing some of the common differentiations between intercultural and multicultural ideologies, several teachers held negative views about the increasing number of minority ethnic students but also pointed to the pro-active role of the Greek government in reversing the 'white flight' and making sure intercultural schools would not be 'ghetto schools':

Ms. Melitsou: The high number of repatriated and foreign pupils within the classroom has a negative effect on the school achievement of the indigenous population. We are afraid of this situation! [...] 
Mr. Gikas: The state should find ways in order to make intercultural schools desirable for the Greek families. It should provide them with the adequate equipment and personnel in order to become appealing and not repellent schools. [...]

Ms. Lelekaki: These children are a reality! Unless we can't change this situation we have to include them, otherwise we will have problems in the Greek society! Whatever we do the aim is to integrate them.

In the direction of 'protecting' the equilibrium within their schools, some school principals asserted that they do not allow the enrollment of 'too many' migrant pupils in their school, believing that it 'safeguarded' the stability between migrant and Greek pupils. Of course, they did not admit to migrant parents the real reason for which they did not enroll their children, but they claimed that this is because their school is 'full':

Mr. Tzanos: It is my main concern to protect the stability of my school; too many migrant students in the classroom can decrease the classroom's school success! Many Greek parents avoid register their children to schools with many migrant pupils, they believe that migrant pupils are a treat to for their child's good attainments and appropriate behavior...I am trying to avoid this unpleasant situation, so I say to migrant parents that our school is already fully booked.

Another example of this policy-practice gap is that according to the aforementioned 1999 Presidential Decree (as well as subsequent immigration laws), migrant students could be taught their mother tongue in schools where there is sufficient number of 'foreigners'. Teachers with qualifications to teach mother tongues, culture and history could thus usefully be employed. Where no Greek teachers are available, the Presidential Decree provides the opportunity to teachers from minority groups to be appointed in reception and tutorial classes provided they meet the qualifications and standards set out by the MoE.

Unfortunately, in practice, it was left to the initiative of enthusiastic teachers whether they would set up after-school mother-tongue classes but this was not part of mainstream 
schooling at the time of data collection. It is also still deeply problematic that, after nearly three decades of immigration, Greek policymakers, academics and educators alike still officially employ terms such as 'foreigner' or 'alien' rather than acknowledging the possible existence of hybrid identities such as Greek Polish or Bulgarian Greek. This implies that immigrants have often been conceptualized as 'foreigners' or 'others' because until recently they lacked Greek citizenship and, to date, there has been no serious public or academic debate challenging these ingrained insensitivities. This might change when the first wave of second-generation students enters the schooling process. The education system continues to stress the significance of Orthodoxy in the self-identification of the Greek nation and in its distinction from the 'others' despite the formal introduction of intercultural education in 1996 and the setting up of reception and tutorial classes as additional support measures in 1999. Although several of our interviewees, though not necessarily within the MoE itself, are more forward-looking today than in 2001, national and intercultural issues are still perceived to be somewhat incompatible and the ethnocentric concept of nationhood has not been reconceptualized to include all the allogeneis migrants.

\section{Balancing cultural diversity and social cohesion}

Issues of how to balance cultural diversity and social cohesion were well expressed amongst several respondents, both in 2001 and 2007. Unfortunately, little progress has been made despite a curricular reform in 2003 which incorporated a European and intercultural dimension under the general principle of strengthening cultural and linguistic identity within a multicultural society. One respondent noted that:

Mr. Karabekos: I believe that a common school for all the pupils where they will attend lessons in the Greek language but at the same time exist classes where they can attend some language lessons in their mother tongue. There will be many of these classes that 
are addressed either to beginners, to semi-advanced or to advanced pupils. My belief is that we must respect the difference within the same class and not to exclude it.

Six years later, the progressivists including Ms. Papadopoulos (the history advisor from the Pedagogical Institute) were still pointing towards the discrepancies that exist in Greece between differently located groups of policymakers but also that balancing social cohesion and cultural diversity should be the main policy concern:

D.F.: If you take those three dimensions - the national, European and intercultural which of these would you say the curriculum should promote and why?

Ms. Papadopoulos: I don't agree with the separation, you know. I think there must be a synthesis of all the three. Because what is national nowadays without multicultural? What is European without the national of all the nations of Europe? There is no European history without the national histories of the European nations. So perhaps it gives us a help to measure things when we separate but, in fact, when we have a book and when we want to teach history to children we must synthesize all these things. It's not a diplomatic answer; it is what I believe for history teaching but also generally. (...) Nowadays immigrants are agents of the national history of the nation they live in. (...) We say that our economy is developing or under-developing. Do not immigrants take part in this? (...) And what our students must understand is not that I am here Greek, you are there German [European] but what I say about 'us'.

Despite recent curricular reforms, teaching history in Greece is still far more ethnocentric compared with other European countries; topics that deal with migration-related issues are fewer in subjects like history, geography and citizenship education than in several other countries in Europe (see Faas 2011b). These slow and modest approaches to transform ethnocentric curricula into more inclusive learning approaches contrast with the need to manage diversity in education and to promote social cohesion as well as diversity. This was clearly expressed in the curriculum introductory notes by the president of the Pedagogical Institute. Professor Alachiotis noted that 'the fabric of society changes, becoming enriched with 
diverse cultural, linguistic, national and socio-economic characteristics' (Government Gazette 2003, 9). For this reason, he continued, it is important that students develop greater appreciation and understanding of different cultures and that the government discards the possibility of imposing a monocultural model. Although recognition of ethno-cultural diversity has now taken place, the intercultural dimension in the new cross-thematic Greek curriculum remains underdeveloped. This is particularly the case if we compare Greece with other European migration societies.

\section{Discussion and conclusions}

There are several issues arising from the discourses of policymakers and other education stakeholders. Our combined studies from 2001 and 2007 revealed a range of thematic issues in the direction of an effective implementation of intercultural education. Though these studies took place some years ago, their findings are very indicative of the current multicultural situation in Greece. On the one hand, there is a division in views between traditionalists (such as senior MoE officials and several teachers/head teachers) and progressivists (mostly educational actors within the Pedagogical Institute). In both groups, however, there seems to be widespread agreement that intercultural education often borders to assimilation, with emphasis on learning Greek language and culture, ignoring languages of minority pupils and their cultural backgrounds. Interculturalism within schools therefore promotes the recognition of the cultural diversity usually through folkloristic celebrations without moving toward acceptance of different cultures and religions. Another finding is that the majority of school officials tended to follow a humanitarian approach in their treatment of repatriated and other migrant students, whereas MoE officials seem to prioritise school management and functioning with lower costs and funding. 
On the other hand, school actors pointed out the need for appropriate education and training of teachers on intercultural issues, in the form of continuing education and of inservice training. They also stressed the need for appropriate books and school curricula, written according to the principles of intercultural education. Representatives from the MoE highlighted the necessity for the implementation of intercultural education within schools and universities and expressed the need for training teacher experts on pedagogical issues. Nearly all informants agreed that appropriate schoolbooks and well-trained teachers are crucial for the successful implementation of intercultural education. Similarly, school cooperation with local counseling services and social workers could help native pupils, immigrant pupils and teachers resolve possible disputes and overcome prejudice and stereotypical attitudes.

The themes raised in this article are important intercultural educational issues in a range of countries (see Portera and Grant 2010). Also, the views expressed by school actors in Greece are similar to suggestions and ideas stated by in-service teachers in other countries which had faced migration challenges at an earlier stage. Indeed, student teachers' preparation for teaching in multicultural classes is a core issue in their undergraduate education which is associated with relevant education programmes based on transformative goals of multicultural education (Wells 2008) as well as experiential programs which target to raise teachers' prejudice and cultivate, instead, beliefs favourable to diverse student populations and create a frame for culturally relevant teaching (Groulx and Silva 2010).

Moreover, there is a need for policymakers to move away from the idea of seeing cultural and religious diversity in Greek schools as a 'problem' needing special educational approaches. Instead of confining intercultural education to 26 intercultural schools, it is important to realize the need to diffuse the intercultural approach within the entire schooling system for all the students. Key actors at the MoE should work in the direction of designing 
new, flexible educational programmes with intercultural dimensions, addressed to all pupils that will permeate the entire public schooling system.

Another important dimension arising from our combined work is the need for adequately educated teachers. Nowadays, teachers work in multicultural classes which call for appropriate teaching approaches, flexible curricula and additional educational measures that support teachers and enhance the learning of all students. As argued by Ensign (2009), teacher education programmes need to develop an orientation with multiculturalism and social justice at the centre, if they want their prospective teachers to be successful with all students. On the other hand, stakeholders also highlighted the necessity for the implementation of intercultural education principles within schools and universities. They felt that there is a great need for teacher experts on intercultural and bilingual education issues, who, at the same time, have obtained multicultural sensitivity and understanding through adequate pre-service programs (Owen 2010).

Unfortunately, the MoE has so far not made intercultural education a political priority. On the contrary, during the last five years, the MoE reduced the number of tutorial and support classes year after year, arguing that the aim is mainstream classes for all pupils. In 2010, a new measure has been established, so-called classes of educational priority zones with the aim of 'provid[ing] a supportive content for combating school drop-out, the equal integration of all pupils, without discriminations, in the educational system, in the frame of a total approach' (paragraph 13). The replacement of tutorial and reception classes with classes of 'educational priority zones' is triggered by reductions in the MoE budget in the wake of the wider economic and financial meltdown in Greece.

As the analysis of the above discourses in 2001 and 2007 highlighted, the boundaries of these narratives are not always clear. Thus, in many cases views of key informants who participated in these studies can overlap. Our evidence suggests that Greek policymakers and 
other stakeholders have not still found a balance between maintaining social cohesion and fostering diversity within public schools with policies addressed to all pupils and measures that would support the learning capital of migrant and native pupils. There is urgent need for implementing more inclusive educational approaches in public educational system, policies that meet the needs of contemporary multicultural Greece and take into consideration the new economic pressures and societal needs. With new general elections and a possible end of the centre-left government looming in early 2012, it remains to be seen whether the MoE with the new educational measures that are being implemented in schools from 2010-11 and the intercultural educational materials being developed in university departments will start transforming multicultural public schools into inclusive intercultural ones. Good intentions are not enough; their underlying aim is what counts most (Gorski 2009). Policymakers have to create effective integrative educational approaches in mainstream schools in accordance with the societal needs of a contemporary multicultural Greek society.

\section{Notes}

1. The absence of a ius soli, at least insofar as second-generation immigrants were concerned, could be explained by the fact that Greece had only recently been transformed from an emigration to an immigration society.

2. The first study, 'Multi-Cultures in Greece: New Challenges for the National Educational System', was carried out in 2001 by the first author during her time as Research Fellow at the London Institute of Education, supported by the Greek Department of Economics.

3. The second study, 'Multicultural Europe' was carried out in 2007 by the second author and supported by the European Commission through a Marie Curie Intra-European Fellowship. This project was affiliated to the EMILIE project, coordinated by the Hellenic Foundation for European and Foreign Policy: http://emilie.eliamep.gr/category/reports. 


\section{References}

Antoniou, D. 2005. Western Thracian Muslims in Athens: From economic migration to religious organisation. Balkanologie, vol.9, no.1-2: 3-25.

Avdela, E. 2000. The teaching of history in Greece. Journal of Modern Greek Studies, vol.18, no.2: 239-253.

Banks, J.A. 2004. Multicultural education: Historical development, dimensions, and practice. In Handbook of research on multicultural education, eds. J.A. Banks and C.A.M. Banks. New York: Macmillan.

Bombas, V.L. 2001. Linguistic and non-linguistic issues of 'our foreign students': The opinion of school principals as an opportunity for reflection and dialogue. Paper presented at the Annual Convention of Intercultural education in Patras, Greece.

Booth, T. 2003. Review of Interculturalism, education and inclusion by J.S. Gundara. British Journal of Educational Studies, vol.51, no.4: 432-433.

Damanakis, M. 2005. European and intercultural dimension in Greek education. European Educational Research Journal, vol.4, no.1: 79-88.

Dimakos, I.C. and K. Tasiopoulou. 2003. Attitudes towards migrants: what do Greek students think about their immigrant classmates? Intercultural Education 14, no. 3: 307-316.

Ensign, J. 2009. Multiculturalism in four teacher education programs: for replication or transformation. Multicultural Perspectives, vol.9, no.3: 169-173.

Faas, D. 2010. Negotiating Political Identities: Multiethnic Schools and Youth in Europe. Farnham: Ashgate.

Faas, D. 2011a. Between Ethnocentrism and Europeanism? An exploration of the effects of migration and European integration on curricula and policies in Greece, Ethnicities, vol.11, no.2: 163-183. 
Faas, D. 2011b. The Nation, Europe and Migration: A comparison of geography, history and citizenship education curricula in Greece, Germany and England, Journal of Curriculum Studies, vol.43, no.4: 471-492.

Goodhart, D. 2004. Too Diverse? Prospect Magazine 95, 30-37.

Gorski, P. C. 2009. Good intentions are not enough: a decolonizing intercultural education, Intercultural Education, vol.19, no.6: 515-525.

Gotovos, A., Markou, G. 1984. The Re-integration of Repatriated Pupils: A Theoretical Approach. In School re-integration of repatriated pupils: Problems and perspectives, eds. Gotovos, A., Markou, G. Athens: Ministry of Education.

Government Gazette. 1996. Law 2413 on Greek Education Abroad, Intercultural Education and Other Provisions. A124, 17 June.

Government Gazette. 1999. Ministerial Decree on Intercultural Education: Establishment and Functioning of Reception and Support Classes. B1789, 28 September.

Government Gazette. 2001. Law 2910 on Entry and Stay of Aliens in Greek Territory: Acquisition of Greek Citizenship by Naturalisation and Other Provisions. A91, 2 May.

Government Gazette. 2005. Law 3386 on Entry, Residence and Social Integration of ThirdCountry Nationals in the Hellenic Territory. A212, 23 August.

Government Gazette. 2004. Law 3284 on the Ratification of the Code of Greek Citizenship. A217, 10 November.

Government Gazette. 2010. Law 3838 on Greek Citizenship and Political Participation of Homogeneis and Legally Resident Migrants and Other Regulations, vol.1, no.49.

Groulx, J. and C. Silva 2010. Evaluating the development of culturally relevant teaching. Multicultural Perspectives, vol.12, no.1: 3-9. 
Guiraudon, V. 2006. Different nation, same nationhood: The challenges of immigrant policy. In Changing France: The politics that markets make, eds. Pepper D. Culpepper, Peter A. Hall, and Bruno Palier. Basingstoke: Palgrave Macmillan.

Gundara, J. S. 2000. Interculturalism, education and inclusion. London: Paul Chapman.

Kastoryano, R. 2006. French secularism and Islam: France's headscarf affair. In Multiculturalism, Muslims and citizenship: A European approach, eds. T. Modood, A. Triandafyllidou and R. Zapata-Barrero. London: Routledge.

Markou, G. 1994. Intercultural education in multicultural Greece. European Journal of Intercultural Studies, vol.4, no.3: 32-43.

Modood, T. 1997. Introduction: The politics of multiculturalism in the new Europe. In The politics of multiculturalism in the new Europe: Racism, identity and community, eds. T. Modood and P. Werbner. London: Zed Books.

Modood, T. 2007. Multiculturalism: A Civic Idea. Oxford: Polity Press.

Modood, T., A. Triandafyllidou and R. Zapata-Barrero eds. 2006. Multiculturalism, Muslims and citizenship: A European approach. London: Routledge.

Nieto, S. and P. Bode. 2007. Affirming diversity: The socio-political context of multicultural education. Boston: Allyn and Bacon.

Nikolaou, G. 2000. The education of migrant pupils in school. Athens: Ellinika Grammata.

Olsen, L. 1997. Made in America: Immigrant students in our public schools. New York: The New Press.

Owen, P. 2010. Increasing Preservice Teachers' Support of Multicultural Education. Multicultural Perspectives, vol.10, no.1: 18-25.

Palaiologou, N. 2004. Intercultural Education and Practice in Greece: Needs for Bilingual Intercultural Programmes, Intercultural Education, vol.15, no.3: 317-329. 


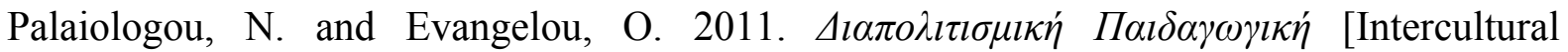
Pedagogy. editions, Pedio] (in Greek).

Parekh, B. 2000. Rethinking multiculturalism: Cultural diversity and political theory. Basingstoke: Palgrave.

Portera, A. and C.A. Grant 2010. Needs of education for the global world. Multicultural and intercultural education in different countries. New York: Routledge.

Sze, F., and D. Powell. eds. 2004. Interculturalism: Exloring critical issues. Oxford: Interdisciplinary Press.

Ter Wal, J. 2007. The Netherlands. In European immigration: A sourcebook, eds. A. Triandafyllidou and R. Gropas. Aldershot: Ashgate.

Tsoukalas, C. 2002. The irony of symbolic reciprocities: The Greek meaning of Europe as a historical inversion of the European meaning of Greece. In The meaning of Europe: Variety and contention within and among nations, eds. M. Malmborg and B. Stråth. Oxford: Berg.

Triandafyllidou, A. 2011. (In)tolerance of difference in Greek schools: The case of migrant and Roma children. http://www.eui.eu/Projects/ACCEPT/Home.aspx

Triandafyllidou, A., and M. Veikou. 2002. The hierarchy of Greekness: Ethnic and national identity considerations in Greek immigration policy. Ethnicities, vol.2, no.2: 189-202.

United Nations Educational, Scientific and Cultural Organization. 2006. Guidelines on intercultural education. Paris: United Nations Educational, Scientific and Cultural Organization.

Vasta, E. 2007. From ethnic minorities to ethnic majority policy? Multiculturalism and the shift to assimilationism in the Netherlands. Ethnic and Racial Studies, vol.30, no.5: 713-741.

Vertovec, S. 1999. Migration and social cohesion. Aldershot: Edward Elgar. 
Wells, R. 2008. The global and the multicultural: opportunities, challenges, and suggestions for teacher education. Multicultural Perspectives, vol.10, no.3: 142-149.

Wood, P., C. Landry and J. Bloomfield. 2006. Cultural diversity in Britain: A toolkit for cross-cultural co-operation. York: Joseph Rowntree Foundation.

Zambeta, E. 2000. Religion and national identity in Greek education. Intercultural education, vol.11, no.2: $145-55$.

Zirkel, S. 2008. The influence of multicultural educational practices on student outcomes and intergroup relations. Teachers College Record, vol.110, no.6: 1147-1181. 